\title{
Do Icônico ao Simbólico. Estratégias para a Construção do Sentido
}

\author{
From Iconic to Symbolic. \\ Strategies for the Construction of Meaning
}

Carolina Lindenberg Lemos

USP

carolina.lemos@gmail.com

Resumo: Discutiremos neste artigo, por meio da análise de um textoobjeto, a construção concessiva da tensão considerando elementos sutis e variações mínimas, mostrando, assim, que configurações discursivas diferentes e contraintuitivas podem levar ao impacto. $O$ contexto de um estudo aplicado nos permitirá mostrar o proveito de usar as categorias tensivas para a análise tanto da expressão quanto do conteúdo, além do ganho de apreender os planos separadamente para fins de contraste. Para chegar a esses dois objetivos, analisaremos inicialmente o caminho que vai do icônico ao simbólico nos aspectos verbal, sonoro e visual. Isso nos levará a discutir a passagem do não saber ao saber no plano da enunciação. Enfim, trataremos do papel da figuratividade na construção tanto dos elementos narrativos quanto na apreensão dos valores. Ao apresentar uma estratégia de construção do impacto no texto e uma forma de conjugação das análises da expressão e do conteúdo, este artigo visa a criação de uma via mais explícita para a incorporação das categorias tensivas às aplicações práticas da teoria.

Palavras-chave: categorias tensivas; relação expressão-conteúdo; iconicidade; figuratividade; enunciação. 


\begin{abstract}
We discuss here, by means of the analysis of a textual object, the concessive construction of tension arising from subtle elements and minimal variations. We thus show how different and counterintuitive discursive configurations may lead to the creation of impact. The context of an applied study will allow us to show the productiveness of using tensive categories to the analyses of both expression and content, as well as the gain of studying each plane separately so they can be contrasted afterwards. In order to reach these two objectives, we will initially analyze the path from iconic to symbolic in the verbal, sound and visual aspects. This will lead us to discuss the passage from the state of not knowing to that of knowing on the enunciation plane. Finally, we will deal with the role of figurativity in the construction of narrative elements as well as the apprehension of values. In presenting a strategy for the construction of impact in the text and a way to conjugate the analyses of the expression and the content planes, this article aims at the creation of a more explicit path to the incorporation of tensive categories into practical applications of the theory.
\end{abstract}

Keywords: tensive categories; expression-content relation; iconicity; figurativity; enunciation.

Recebido em 31 de março de 2015. Aprovado em 08 de setembro de 2015.

Pois aquilo é ferro forjado. Flores criadas numa outra língua. Nada têm das flores de fôrma moldadas pelas das campinas.

Forjar: domar o ferro à força, não até uma flor já sabida, mas ao que pode até ser flor se flor parece a quem o diga. 


\section{Introdução}

A construção do impacto nos textos é frequentemente associada à surpresa da entrada inesperada de objetos no campo de presença do sujeito. Entretanto, as manifestações textuais são múltiplas e podemos supor que, entre os limites da surpresa total e do tédio absoluto, uma série de estratégias podem ser convocadas para a construção da eficácia tensiva de um texto. Mais ainda, podemos aventar que, se tomamos como referência elementos desacelerados e construímos com base neles uma cifra tensiva de impacto, essa configuração como um todo é surpreendente. Diremos talvez que estamos numa lógica concessiva da construção textual; embora nossos elementos sejam de pouco impacto, a resultante é impactante e a eficácia textual é máxima.

De fato, a partir de elementos narrativos e figurativos muito simples, o filme publicitário sob investigação nas páginas que seguem tornou-se um clássico da publicidade norte-americana. Trata-se do primeiro filme de uma série de publicidades televisivas para a cerveja Budweiser, veiculado no intervalo da competição nacional de futebol americano de $1995 .{ }^{1}$ Foi de tal forma feliz na sua construção que entrou para a memória - potencializou-se. Os personagens dessa série ficaram, então, conhecidos como "the Budweiser Frogs" (os sapos da Budweiser).

Propomos, assim, investigar a configuração discursiva desse registro minimalista em relação ao componente enunciativo, a fim de mostrar de que maneira os elementos figurativos e narrativos do texto regulam o saber no plano da enunciação. Essas relações entre enunciado e enunciação mostram-se regidas por variações de andamento. Noção emprestada da teoria musical, exploraremos o emprego da noção de andamento no conteúdo, segundo as propostas de Claude Zilberberg (2006, 2011, 2012), e sua composição com a subdimensão da espacialidade. Visto que têm origem no tratamento da expressão musical, exploramos a possibilidade de empregar as mesmas categorias de andamento e espacialidade para a descrição da expressão também nesse contexto. Sua composição, entretanto, revelará curva distinta àquela

\footnotetext{
${ }^{1}$ O filme original de 1995 foi criado pela agência DMB \& B / St. Louis e foi dirigido por Gore Verbinski. Pode ser visto em: $<$ http://www.youtube.com/watch?v=i4Uje7IwVY4>. Uma compilação dos filmes publicitários ligados a essa sequência pode ser encontrada em $<$ http://www.youtube.com/watch?v=f3mXaATLeRM $>$.
} 
do conteúdo. A comparação das curvas nos leva de volta à discussão da escolha minimalista do vídeo que se revela de grande impacto, configurando, assim, a eficácia mencionada acima de uma publicidade que entra para a memória.

$\mathrm{O}$ artigo encerra-se com uma abertura: o procedimento desenvolvido para a análise desse objeto semiótico estende-se para além de seus limites. A análise independente de cada plano - expressão e conteúdo-, seguida de seu contraste, mostra-se coerente com as bases teóricas da semiótica (HJELMSLEV, 2003, p. 27-37, p. 53-64) e, ao mesmo tempo, flexível e adequada a outras análises de textos. Nesses termos, a análise particular abre-se para uma dimensão maior da análise semiótica.

\section{Da natureza à cultura}

Nesta análise, examinamos primeiramente o modo pelo qual referências icônicas podem ser usadas para provocar um efeito de estranhamento, que apenas encontrará solução quando esses mesmos elementos convergirem para o registro simbólico. ${ }^{2} \mathrm{O}$ corpus dessa investigação, conforme anunciamos, é a campanha publicitária da Budweiser, lançada em 1995. Embora vamos nos ater ao primeiro anúncio que deu origem à série, faremos, por vezes, menção a outros filmes que fizeram parte de toda a campanha.

Esse primeiro filme se inicia com o enquadramento de um sapo num lago, que coaxa repetidas vezes (ver Figura 1):

\footnotetext{
${ }^{2}$ Termos originários da semiótica de C. S. Peirce, "icônico" e "simbólico" estão aqui inseridos no contexto da semiótica da escola de Paris de caráter imanente. Sendo assim, não definiremos essas noções em relação a um referente externo, mas numa relação entre semióticas. Uma referência icônica trata de um elemento de uma semiótica (nesse caso, o som emitido pelos bonecos em forma de sapo no vídeo), que aponta para um elemento da semiótica do mundo natural (em nosso caso, o coaxar de um sapo), criando, assim, uma ilusão referencial (GREIMAS; COURTÉS, 2011, p. 250-251). Em oposição, uma referência simbólica aponta exclusivamente para um sistema convencional de signos.
} 


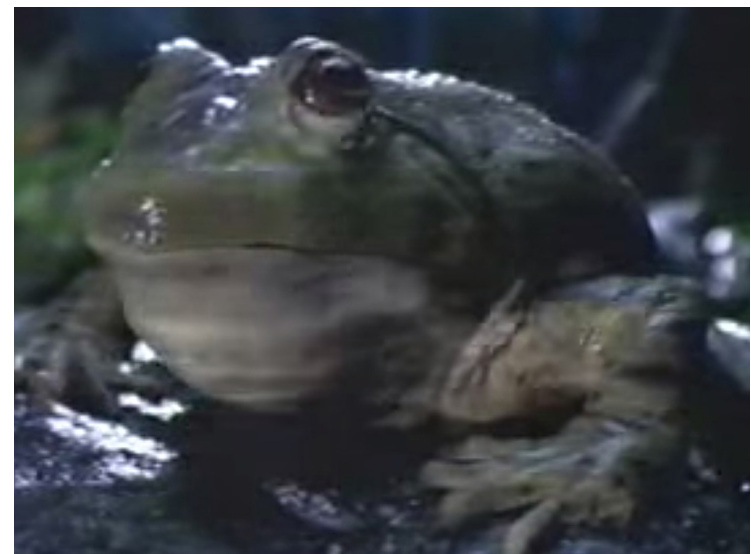

Figura 1 - primeiro sapo ("Bud")

A ambientação no lago com os sons de grilos e pererecas cria a cena. Os sons de fundo geram o elemento contínuo que será pontuado pelo coaxar do sapo. Cria-se, assim, um paradigma, uma isotopia da natureza que é a chave para a leitura icônica. Aos poucos, o coaxar de três sapos (ver Figura 2 com os três sapos) vai se destacando e uma série de elementos parecem ficar fora de lugar, para que seja possível fazer uma leitura plenamente icônica de toda a cena.

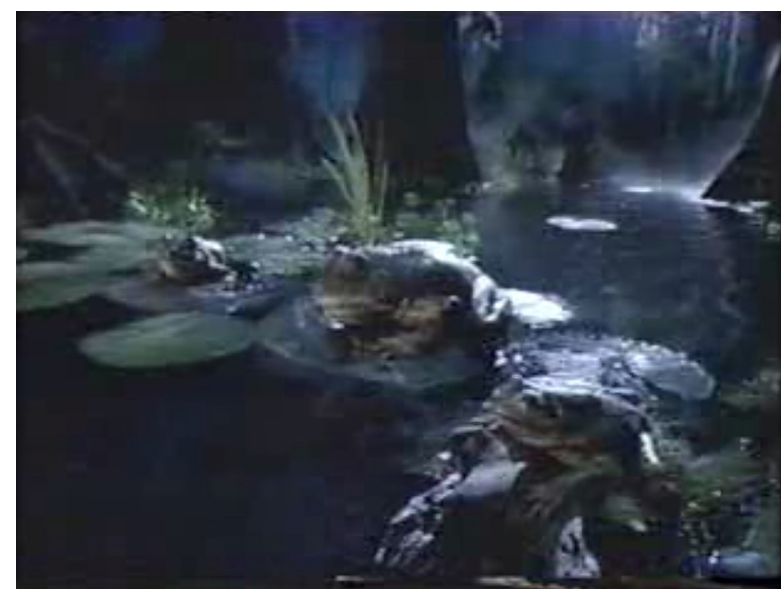

Figura 2 - três sapos 
Ao fim da publicidade, o enunciatário percebe que o ruído dos sapos deve, diferentemente, ser lido no registro da cultura: são sapos humanizados, que falam as sílabas da marca de cerveja Budweiser, lidas por eles do letreiro luminoso de um bar à sua frente.

Esse percurso de leitura do texto, que perfaz a passagem do registro da natureza para o registro da cultura será espelhado em variadas dimensões. Assim, da mesma forma que é convidado a seguir a via de leitura que parte da natureza em direção à cultura, o enunciatário também é levado a realizar outros percursos que vão: (i) da substância dos sons desconexos dos sapos à forma manifestada no nome de uma marca reconhecível e contextualizada; (ii) do não saber (aqui entendido como uma suspensão do entendimento gerado pelo efeito insólito desses sapos que não se encaixam bem no "contexto natural" criado pelos elementos de ambientação) ao saber (quando da resolução do filme); e, como já sugerimos, (iii) do icônico ao simbólico.

Levando em consideração as questões mencionadas até aqui, exploraremos a seguir o papel desempenhado pelo andamento ${ }^{3}$ na passagem do icônico ao simbólico, a construção do efeito insólito e a composição dos elementos de expressão e conteúdo nessa construção.

\section{Andamento e saber}

Parece bastante plausível pensar que é necessária uma certa moderação no andamento da apresentação de conteúdos num texto. A apresentação excessivamente rápida de conteúdos num texto pode gerar confusão no enunciatário. Não nos referimos aqui a uma aceleração da expressão, embora essa também possa causar problemas. Imagine-se a possibilidade de assistir a um filme, do começo ao fim, rodado duas vezes mais rápido do que o habitual. Certamente ocorrerão confusões nisso também. Mas, como dizíamos, estamos no registro do conteúdo e de como um conteúdo é apresentado ao enunciatário. Se houver um fluxo muito grande de informações novas sendo apresentadas em sequência, o enunciatário pode se sentir saturado e, por conta disso, não mais ser

\footnotetext{
3"Andamento" é uma noção musical que trata da velocidade de execução de uma peça (MICHAELIS, 2012, verbete "andamento"). A Seção 2 é dedicada a definir a transposição dessa noção para a semiótica, especialmente no que toca a relação com o enunciatário.
} 
capaz de acompanhar o sentido do texto. Saltos e elipses, em que não é possível estabelecer a ligação entre causa e consequência, por exemplo, criam, no texto, um efeito de sentido de aceleração e, por isso, exigem do enunciatário maior esforço para recuperar a coesão entre as partes do texto. A assimilação de novos conteúdos depende de contextos familiares, da existência de um equilíbrio entre novo e conhecido. No caso de uma aceleração excessiva, seria necessário ao enunciatário retraçar seu caminho para recuperar o fio perdido.

E como seria o caso de um texto demasiadamente desacelerado? Se pensássemos, por exemplo, num texto em que cada novo elemento fosse introduzido muito lentamente, distante de outras novas informações que poderiam se acrescentar, acompanhado de um excesso de detalhes e conteúdos já conhecidos, sem nenhum espaço para inferências, dificilmente teríamos um enunciatário disposto a acompanhá-lo em seu andamento - em oposição àquele outro que simplesmente não pôde fazê-lo devido à aceleração extrema. Nos dois casos, o texto se perde como objeto para o enunciatário. $\mathrm{Na}$ aceleração, é o texto que escapa ao enunciatário. Na lentidão, o desligamento está associado à perda de interesse.

Naturalmente, esses limites podem ser testados e invertidos. Se a fronteira da lentidão for traçada ainda para mais longe e a introdução de conteúdos se apresentar ainda mais escandida no tempo, é possível se chegar ao limite da memória, e o enunciatário passará, novamente, a não poder acompanhar o texto, por não ser capaz de ligar as partes num único enunciado coerente. ${ }^{4}$

\section{Na publicidade}

Nesse contexto de acelerações e desacelerações, entramos no domínio da publicidade. Não estamos mais, porém, na mesma situação extrema descrita acima, uma vez que a publicidade prima, via de regra, pelo que podemos chamar de bom timing - o ajuste do tempo para causar o maior impacto possível. É assim que o clássico anúncio dos sapos da marca de cerveja americana Budweiser explora as modulações de andamento para criar os efeitos de sentido vistos no texto.

\footnotetext{
${ }^{4}$ Para uma discussão mais detida acerca dos limites máximo e mínimo do andamento e sua relação com a repetição e o ritmo do conteúdo, ver Lindenberg Lemos (2015, p. 117-122).
} 
O filme publicitário da Budweiser trabalha no extremo da desaceleração, mas, em vez de gerar o tédio e o desinteresse que levam o enunciatário a não querer acompanhar o texto, provoca justamente aquilo que se espera do texto acelerado: o não poder entender, nesse caso, o nonsense.

Como vimos acima, o anúncio traz um elemento de continuidade nos sons de fundo que será marcado pelo coaxar dos sapos. O barulho produzido pelo primeiro sapo é, entretanto, sui generis. Lembrando que o filme foi criado para o mercado norte-americano, ${ }^{5} \mathrm{o}$ sapo não reproduz nem exatamente um verdadeiro coaxar, nem a onomatopeia inglesa ribbit, mas produz, num som grave, a sílaba bud [b $\wedge \mathrm{d}]$. Em inglês, essa sílaba compõe por si só uma palavra que pode ser traduzida por "amigo" ou "companheiro". A associação desses elementos naturais do contexto ao falar destoante do sapo constrói um certo estranhamento. ${ }^{6}$ Isso é particularmente acentuado pelo gênero de que o texto faz parte. Fosse um programa televisivo de canais como Animal Planet ou National Geographic, que tratam da vida animal, a sílaba diferente talvez passasse despercebida. No contexto publicitário, sua estranheza sobressai.

Com o desenrolar do filme, a câmera passará a focalizar outros dois sapos, que produzem duas novas sílabas. Á direita do primeiro sapo ("Bud"), o menor dos sapos fala a sílaba weis [wajz]. Em inglês, mais uma vez, a sílaba por si só constitui uma palavra que, com o mesmo som mas outra grafia - wise-, constrói a palavra "sábio". "Bud" e "Weis" alternam algumas vezes até que intervém o terceiro sapo, com a sílaba er [3]. Trata-se, dessa vez, de uma interjeição dicionarizada que demonstra hesitação. No uso popular, também pode ser usada para descrever uma situação estúpida ou uma pessoa de pouca inteligência. ${ }^{7}$

\footnotetext{
${ }^{5}$ Esse filme foi apresentado ao público nos intervalos da $29^{\text {a }}$ versão do Superbowl em 1995. O Superbowl é a final do campeonato de futebol americano nos Estados Unidos e traz, tradicionalmente, algumas das campanhas publicitárias mais caras do ano no país (LA MONICA, 2007).

${ }^{6} \mathrm{O}$ que chamamos de "estranhamento" nesse contexto é tão somente a impossibilidade ou ao menos a dificuldade - de interpretação de dois elementos destoantes colocados lado a lado: no caso, um sapo que fala em meio a um contexto natural. A insistência nesses traços conflitantes vai gerar o que, mais adiante, chamaremos de "efeito de insólito". ${ }^{7}$ Os sapos da Budweiser vieram a ser conhecidos exatamente pelas sílabas que produziam: Bud, Weis e Er (Cf. RAUGUST, 1998).
} 
Ao final do anúncio, o enunciatário é capaz de montar as sílabas para formar o nome da cerveja: bud-weis-er. Entretanto, de início, as sílabas são apresentadas fora de ordem e muito lentamente. A sequência de apresentação das sílabas até que se forme pela primeira vez o nome da marca é a seguinte:

'bud-bud-weis-bud-bud-weis-bud-er-bud-weis-bud-er-weis-bud-bud-weis-er' .

Uma vez que as sílabas encontram a ordem que forma o nome da marca, altera-se sua velocidade de produção. Se antes tínhamos uma sílaba a cada um ou dois segundos, agora temos todo o conjunto produzido em aproximadamente um segundo, sendo repetido também a cada segundo.

A apresentação de conteúdos, como fizemos supor acima, é de tal forma lenta e desordenada que o enunciatário não é capaz de compor a palavra que esclarece o suspense construído no texto. Durante a maior parte do filme, o enunciatário permanece num estado de suspensão do entendimento que gera um efeito do que poderíamos chamar de insólito - um estado em que o enunciatário é capaz de compreender cada um dos elementos presentes, mas parece não haver uma razão, um sentido, para que os elementos estejam dispostos e relacionados daquela maneira.

A criação desse efeito de "insólito" se dá, como dissemos, pela associação entre a ambientação natural e os sapos que falam sílabas um tanto misteriosas. No entanto, esse efeito é potencializado pela dimensão temporal, ou seja, a insistência e a extensão no tempo desse jogo aparentemente sem sentido provocam um acréscimo gradual de tensão. Ao mesmo tempo, a reiteração do enquadramento nos sapos e do vai e vem das sílabas deixa claro que, no desfecho da narrativa, a solução do anúncio virá também pelo coaxar. De fato, uma vez que as sílabas começam a ser faladas na sequência que forma a marca, o jogral dos sapos se altera: a palavra é repetida mais vezes e de forma mais acelerada, antes que a câmera mude de direção, mostrando as costas dos sapos e o letreiro luminoso onde leem insistentemente "bud-weis-er". Ao final do anúncio, quando o coaxar dos sapos adquire uma nova dimensão, percebemos que as sílabas do início formavam um verdadeiro paradigma que trazia, virtualizada, a marca da cerveja. A marca é então atualizada por meio da sintagmatização das sílabas, ou seja, quando as sílabas ganham uma ordem constante e uma periodicidade, fazendo 
com que formem um conjunto. Podemos dizer, nesse sentido, que, no momento em que subitamente se revela a marca Budweiser, ocorre a ultrapassagem de um limite, resultado da formação repentina de uma totalidade que ainda não se podia adivinhar na declinação progressiva das suas sílabas-partes. Por outro lado, quando surge o letreiro, a marca ganha densidade de presença. A focalização do luminoso corresponde, de um lado, à realização do nome que se formou no cantar dos sapos, de outro lado, à compreensão da "origem" da fala dos sapos, que liam de um letreiro. A marca realizada no letreiro traz a perspectiva de uma conjunção plena dos personagens e do enunciatário com o objeto.

A consciência das sílabas se dá por meio de uma reconstituição empreendida pelo enunciatário numa retroleitura que se segue à compreensão global da peça. É nesse momento que surge a interpretação de que os sapos estavam todo o tempo lendo o luminoso. Dessa forma, há uma inversão de direção entre enunciação e enunciado. Nesse, o nome da marca vai se construindo de suas partes (as sílabas) até formar uma totalidade, em outros termos, do paradigma ao sintagma. Na enunciação, é apenas depois de termos a solução linguística dos ruídos emitidos pelos sapos, ou seja, a composição do nome da marca, que podemos reconstituir o paradigma inicial, a compreensão de que os ruídos eram, na verdade, sílabas.

\section{Contribuições da figuratividade}

Numa publicidade de narrativa tão econômica, é de se perguntar como se constroem os sujeitos. De início, podemos vê-los como meros sujeitos de um fazer mecanizado, da repetição constante de uma mesma sílaba. No entanto, se investigarmos um pouco mais em detalhes os elementos figurativos colocados, notaremos algumas sutis diferenças na configuração temática de cada um dos atores.

Primeiramente, como já levantamos acima, os nomes dos sapos, $B u d$, Weis e Er, associam-lhes diferentes papéis temáticos: o amigo, o sábio e o tolo. ${ }^{8}$ Em seguida, podemos perceber uma diferença de altura

\footnotetext{
${ }^{8}$ É curioso notar que essa campanha teve continuação numa sequência de anúncios que exploravam mais os elementos narrativos. Numa delas, Weis é eletrocutado por um lagarto enciumado do sucesso dos sapos. No filme seguinte, é Bud - o amigo - quem vai confrontar o lagarto em defesa de Weis. Os nomes também evocam personagens tradicionais (com
} 
na voz de cada sapo. Bud é mais grave, Weis mais agudo e Er tem altura intermediária. Essa variação em altura parece combinar com as diferenças em tamanho. Bud é o maior, Weis, o menor e Er tem tamanho médio.

Se nos voltarmos mais uma vez para as variações no tempo de execução das sílabas, notaremos que Bud e Er são mais lentos e Weis quebra o ritmo, por vezes, ao se precipitar na hora de entrar com sua fala; chega mesmo a acavalar sua sílaba à sílaba de Er, num dado momento. Ora, se consultarmos a palavra sábio em dicionários de língua inglesa e portuguesa, encontraremos, em ambos os casos, semas desacelerados como parte de sua definição, como prudente e judicioso, por exemplo. Podemos, assim, entender essa precipitação de Weis como irônica e, dessa forma, contribuindo para o efeito geral de comicidade. Er, por outro lado, está perfeitamente inserido em seu papel de tolo, uma vez que é o mais lento do grupo. Não só é o último sapo a começar a participar do jogral como também é o que fala menos vezes e chega a atrasar sua entrada na terceira vez. Há, assim, uma quebra no ritmo, um desequilíbrio que prepara a resolução. Esse atraso coincide com a primeira aparição do nome da marca na sequência esperada e com o instante anterior ao surgimento do nome compactado num bloco sem intervalo entre as sílabas. A mudança no andamento das sílabas é o começo do fim. A partir de então, todo o mistério em torno da vocalização dos sapos começa a se desvendar, culminando na apresentação do letreiro.

Essa recategorização dos atores do enunciado, como sapos humanizados, também contribui para a criação do efeito "insólito", pois é mais um elemento fora de lugar na cena natural do lago. Por outro lado, diferenças de tempos de entrada de cada um dos sapos podem mostrar que suas falas estão fora de compasso e pedem por um ajustamento que será realizado somente nos instantes finais, próximo à conclusão do texto. Podemos ainda entender essas repetições como um fazer obsessivo de um desejo cristalizado. Em outras palavras, os sapos parecem estar presos a esse letreiro que não conseguem deixar de ler. Visto que o letreiro remete na realidade à cerveja, por meio da marca, podemos inferir que o desejo está atrelado à cerveja. Nesse primeiro filme, isso não passa de uma sugestão, pois de fato não vemos mais do que os sapos, o letreiro e seu fazer repetido.

seus respectivos papéis actanciais) das narrativas populares: o tolo como herói, o sábio como doador (algumas vezes como destinador) e o amigo como adjuvante. 
Entretanto, as publicidades subsequentes da série confirmam essa suposição. Esse desejo inferido do fazer aferrado dos sapos será explorado, por exemplo, numa das muitas continuações propostas para essa campanha publicitária, em que os sapos, depois de muito cantarolar o nome da cerveja, invadem o bar em frente com o letreiro luminoso para roubar a bebida. Essa ligação obsessiva dos sapos com a cerveja constrói uma estratégia concessiva do texto que visa ampliar o impacto e, com isso, o efeito persuasivo da cena: mesmo no mundo natural a marca da cerveja é irresistível ou, de outra perspectiva, a cerveja é capaz de humanizar até mesmo o mundo animal.

\section{Interação entre expressão e conteúdo}

Voltando ao efeito de insólito de que falávamos acima, verificamos que participam de sua criação tanto elementos da expressão quanto do conteúdo. No início, as imagens nos são apresentadas em close ups e planos de conjunto ${ }^{9}$ e, dessa forma, não é muito além dos sapos e de seu entorno imediato que nos é dado ver (ver Figura 3 abaixo com os três sapos em close up). Nesse mesmo momento, o enunciatário começa a ser apresentado aos conteúdos insólitos, dos quais emerge a questão: a que vieram esses sapos atípicos, num contexto não exatamente natural.

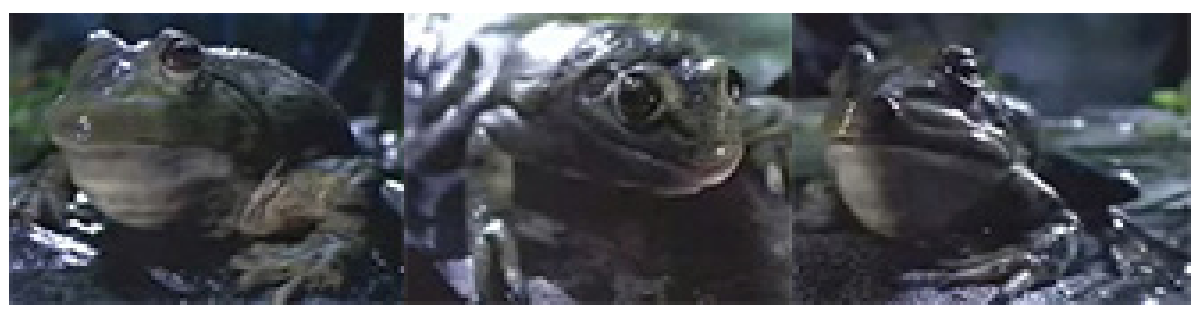

Figura 3 - Três sapos - Bud, Weis, Er

O plano da expressão tem que ser considerado com base nas coerções impostas por esse sistema de significação que é o filme publicitário televisivo. Em nosso caso particular, é necessário, portanto, que se leve em consideração os jogos de câmera que vão determinar a

\footnotetext{
${ }^{9}$ Quando há um personagem no enquadramento, os close ups mostram o rosto e os planos de conjunto apresentam o corpo inteiro. Em nenhum dos casos se vê muito do que está em volta.
} 
configuração da espacialidade e que, ao valorizar uma aproximação das figuras dos atores do enunciado na escolha da focalização, vão apresentá-la de início concentrada. ${ }^{10}$ Note-se que não estamos tratando aqui propriamente daquilo que é apresentado - do conteúdo das imagens. Isso será assunto das observações acerca do conteúdo apresentadas na sequência. Apresentamos aqui tão somente as variações de fechamento e abertura da câmera, ou seja, aquilo que será o veículo dos elementos de conteúdo. Nesse sentido, a focalização se abre paulatinamente e a espacialidade se amplia no plano global para revelar o ambiente em volta, começando pela exposição da lagoa (ver Figura 2), cujos elementos característicos estavam apenas sugeridos pela sonoridade de fundo e pelo pouco que se podia observar ao redor dos sapos, e, se aproximando do final, pela apresentação do bar, com seu efeito ao mesmo tempo surpreendente e esclarecedor do comportamento atípico dos sapos (ver Figura 4 com o bar e o letreiro).

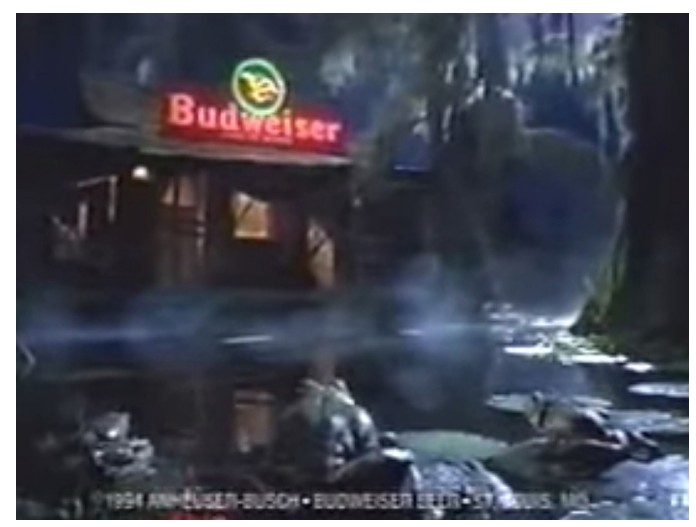

Figura 4 - Bar e letreiro Budweiser

Um outro elemento relevante no plano da expressão é o andamento, que, como vimos, regula a velocidade de apresentação de conteúdos e de expressões. Se tomarmos o coaxar como ponto de partida, vemos que, de início, os sons são introduzidos lenta e esparsamente.

\footnotetext{
${ }^{10}$ Como desenvolvido em Lindenberg Lemos (2010, p. 76-78), a aproximação da câmera tem o papel de exibir pouco da paisagem, apresentando a parte selecionada em muitos detalhes.
} 
Quando as sílabas se combinam em nível sintagmático para formar a marca Budweiser, a velocidade de apresentação cresce para determinar um andamento mais acelerado, gerando uma direcionalidade no sentido da aceleração (ZILBERBERG, 2011, p. 74). Esse movimento de aceleração crescente encontra um correlato numa direção ascendente na tonicidade ligada às vocalizações. A tonicidade está ligada à noção de acento, que se define pelo aumento ou diminuição de altura, duração e força (ZILBERBERG, 2011, p. 289). No caso do filme sob análise, no início as sílabas são desconexas, instáveis, "frouxas", mas, ao final, quando fazem parte da palavra, elas se reúnem num único bloco coeso, no qual se percebe mesmo um pico de acento na segunda sílaba.

Se constatamos uma relevância desses critérios para a organização dos elementos expressivos, podemos, então, associá-los de tal forma a apresentar uma direcionalidade da expressão. Na representação abaixo, escolhemos retratar as subdimensões do andamento e da espacialidade:

Expressão

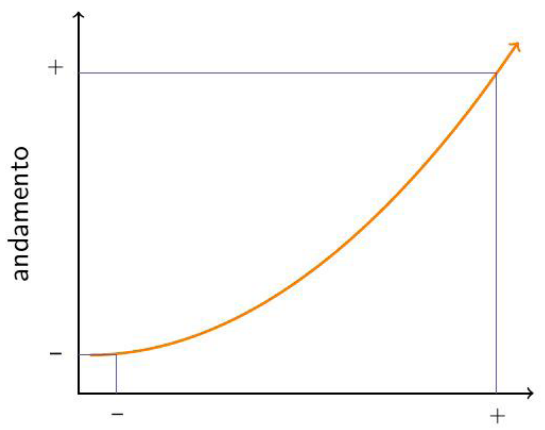

espacialidade

Gráfico 1 - Representação das variações tensivas da expressão

Fonte: a autora

$\mathrm{Na}$ análise do plano do conteúdo do filme, observamos uma direção também ascendente do andamento. Em primeiro lugar, porque as figuras do conteúdo parecem apontar para significações diferentes. Ao enunciatário, são apresentados elementos da natureza e coaxares artificiais que não se encaixam no contexto - formam um fazer repetido 
que não parece ter ordem ou direção. Há, entre esses componentes díspares, um quiasmo. Ao mesmo tempo, vimos que a repetição do jogral dos sapos vai a cada momento recrudescendo o mistério. Assim, quando vão sendo introduzidos os barulhos de fundo e cada um dos sapos e à medida que se desenha esse jogo sem sentido, a tensão vai crescendo. Quando é introduzida a marca da cerveja, é como se houvesse uma passagem abrupta de um regime da desordem para um regime da ordem, em que elementos dissociados subitamente passassem a tomar uma única direção. Em outras palavras, enquanto as sílabas estavam soltas e sem uma ordem definida, a sua apresentação era lenta e variável. Uma vez que são organizadas para formar uma palavra, e as sílabas estão portanto ordenadas, a velocidade de apresentação aumenta e o ritmo torna-se regular. Essa passagem abrupta da desordem inicial à ordem de uma palavra que faz sentido, ao mesmo tempo em que acelera o conteúdo, traz impacto à marca apresentada.

Por outro lado, vemos que o sujeito do enunciado - realizado em superfície pela figura dos sapos - é regido por uma temporalidade a cada momento mais paralisada. No início, ainda é possível perceber algum progresso temporal no texto, na medida que há desigualdades no falar de cada sapo. Entretanto, assim que os coaxares se transformam no nome da marca, ela passa a ser repetida, sem modificação, indefinidamente. Apesar de o filme acabar logo depois disso, a recitação vai sumindo paulatinamente com uma redução gradual de volume, sugerindo que os sapos continuariam a cantarolar sem um fim determinado. A reiteração incessante de um mesmo esquema - seja de elementos singulares, como as sílabas, seja de certos grupos de fatores, como a figuratividade dos sapos - gera uma concentração temporal (Cf. LINDENBERG LEMOS, 2015, p. 122-132). Tudo ocorre como se, apesar de o tempo passar, não houvesse uma verdadeira evolução temporal. Trata-se de um tempo rítmico, cíclico, involutivo (TATIT, 2007, p. 71, ss.). Acerca da canção, Luiz Tatit (2007, p. 75) escreve: "a involução descreve os movimentos melódicos que tendem a sincretizar as duas funções [sujeito e objeto]". Em nosso caso, trata-se da mesma relação entre o fazer repetitivo do sujeito que cria essa estagnação no tempo e a busca pela conjunção total com o objeto. Assim, essa temporalidade refreada se ajusta perfeitamente à apreensão de que o fazer desses animais pode ser uma expressão de um desejo obcecado, de um querer que, apesar de não realizado, não oscila e se mantém forte e constante. 
Percebemos também uma tendência do texto para o fechamento espacial. No primeiro momento, ainda que muito discretamente, há alguns movimentos de cabeça, piscares de olhos. Uma vez que a câmera se distancia, tudo se passa como se esses movimentos deixassem de ser significativos. Só vemos três figuras estanques, pregadas a uma posição, vidradas, a olhar o letreiro. Dessa forma, podemos dizer que se trata de um sujeito que não é capaz de apreender o espaço aberto que o envolve, ficando confinado ao seu objeto de valor. É nesse sentido que, apesar de a câmera revelar um entorno amplo, o espaço figura $1^{11}$ de atuação desse sujeito é restrito, dada a sua perfeita imobilidade. Ademais, a focalização final da câmera também sugere uma concentração da espacialidade, uma vez que três figuras (mais o telespectador, por meio da própria câmera) dirigem seu olhar para um mesmo ponto - o letreiro luminoso -, formando um V, cujo vértice atrai a direção do desejo do sujeito do enunciado e essa parece ser a estratégia buscada -, se não do desejo, pelo menos da atenção do enunciatário. A formulação acerca da atração que o objeto exerce sobre o sujeito traz à baila a discussão sobre a apassivação do sujeito frente ao objeto estético (GREIMAS; FONTANILLE, 1991, p. 30). Ainda que estejamos aqui em outro contexto, a construção de um objeto arrebatador que imobiliza o sujeito se mantém e corrobora a leitura de que estamos diante de um sobrevir, em que, instaurada a marca-objeto, o sujeito passa a um estado de "sofrer" (a influência desse objeto poderoso), e não de agir (ZILBERBERG, 2007, p. 22). Note-se que o fazer dos sapos, ao se mostrar repetitivo e circular, revela não ter direção. Esse fazer sem "sentido" é mais uma constatação de que está representado no filme um sujeito de estado, e não de ação.

$\mathrm{O}$ espelhamento das subdimensões da extensidade ${ }^{12}$ é previsto

\footnotetext{
${ }^{11} \mathrm{O}$ adjetivo "figural" se opõe a "figurativo". Este está ligado à construção de superfície das figuras - nesse caso, ao espaço aberto e exterior do lago. Aquele refere-se a um nível mais profundo daquilo que é percebido pelo sujeito. Em nosso caso, como a atenção dos sapos está dirigida e fixada no letreiro, a espacialidade para esse sujeito é fechada na figura de seu objeto (ZILBERBERG, 1986).

${ }^{12} \mathrm{Em}$ linhas gerais, a dimensão da extensidade na semiótica tensiva se define como aquela ligada aos estados de coisas (em oposição aos estados de alma descritos pela intensidade). Seus valores se distribuem numa escala entre concentração e difusão e reúne em si duas subdimensões: a temporalidade e a espacialidade (ver ZILBERBERG, 2011, p. 257-258).
} 
na teoria, uma vez que a dimensão é composta de temporalidade e espacialidade e a relação ' $e . . . e$ ' determina uma relação conversa (FONTANILLE; ZILBERBERG, 2001, p. 26; ZILBERBERG, 2006, p. 171). Dessa forma, é esperado que as variações de temporalidade e espacialidade corram em paralelo. Da mesma maneira, as subdimensões da intensidade - tonicidade e andamento - são convergentes. Entretanto, o contraste entre subdimensões de eixos diferentes pode resultar em curvas com diferentes configurações e direções. Nesses termos, vemos que a associação do andamento e da espacialidade do conteúdo vai produzir um resultado bastante diferente do esquema da expressão.

\section{Conteúdo}

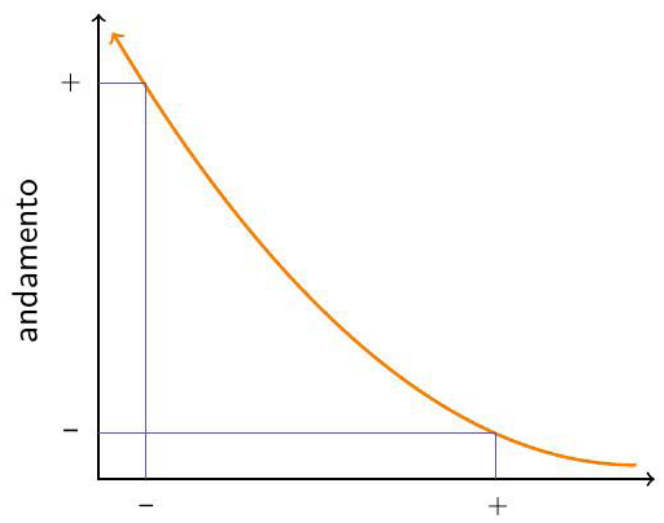

espacialidade

Gráfico 2 - Representação das variações tensivas do conteúdo

Fonte: a autora

Por fim, podemos observar a interação entre o esquema traçado para a expressão e o esquema do conteúdo. Apesar de a espacialidade, no plano da expressão, dirigir-se para a abertura e, superficialmente, vermos uma ambientação externa, à beira de um lago, a análise do estado do sujeito revela uma tendência à concentração espacial na dimensão figural. Por outro lado, andamento de expressão e conteúdo caminham na mesma direção da aceleração. Apesar da direção convergente, a coincidência entre expressão e conteúdo é, nesse caso, mais intrigante do 
que esclarecedora, uma vez que vemos uma tendência inversa em outros textos publicitários analisados (Cf. LINDENBERG LEMOS, 2007; 2010, p. 26-56). O que observamos em geral é uma desaceleração da expressão quando o conteúdo está acelerado, como se o enunciatário precisasse de mais tempo para dar conta dos novos sentidos que se apresentam de maneira apressada. Essa aceleração da expressão - quando talvez se esperasse uma desaceleração, em analogia com os demais textos -, pode ter sua raiz nos comentários que fizemos no início da análise. Esse anúncio parte do limite mínimo da desaceleração e é somente por meio da aceleração que suas partes ganham sentido. Naquele momento, mais desaceleração corresponderia à extinção.

\section{Minimalismo e impacto}

Há muitas formas de generalizar os objetivos da publicidade. Podemos, grosso modo, imaginar três logo de saída: (i) o objetivo de apresentar um produto ou uma marca; (ii) o de convencer que um produto ou uma marca tem certas vantagens ou traz certos valores; e (iii) o de fazer lembrar. O anúncio minimalista dos sapos da Budweiser parece, em superfície, fortemente centrado neste último objetivo. Passamos o filme inteiro às voltas com o nome da marca. Não se apresentam qualidades do produto ou sequer se vê embalagem, textura, referência ao sabor. No entanto, o que fixa essa publicidade na memória é menos a repetição incansável da marca, mas principalmente o impacto produzido.

O suspense crescente seguido da satisfação da descoberta conquista a cumplicidade entre enunciador e enunciatário. Acompanhamos, no texto, a construção de um efeito de plenitude, por meio de uma ampla conjunção entre sujeito e objeto. No enunciado, os sapos, que vivem nesse mundo híbrido, a um só tempo natural e cultural, mostram, com sua recitação obsessiva do nome da cerveja, um desejo cristalizado e, como sugerimos acima, a própria cerveja como um objeto fortíssimo, ${ }^{13} \mathrm{capaz}$ de humanizar seres da natureza. No cantarolar dos sapos, está patente a perfeita conjunção do sujeito com o valor do objeto. Essa conjunção plena será espelhada na enunciação, por meio da relação entre enunciador,

\footnotetext{
${ }^{13}$ Essa formulação remete a uma modalização do objeto. Estamos aqui pensando na atratividade que o objeto exerce sobre o sujeito e que instaura, efetivamente, o liame juntivo entre os actantes. Cf. Greimas e Fontanille (1991, p. 25-26).
} 
mensagem publicitária e enunciatário. A construção de um percurso de descoberta, que culmina numa convergência de todos os sentidos dirigidos para a marca apresentada no final do anúncio, vai convidar o enunciatário a retraçar seus passos a fim de desacelerar a narrativa, para, em retrospectiva, montar novamente a história de seu todo até suas partes nas sílabas iniciais. Essa plenitude deve, então, ser potencializada (memorizada) pelo enunciatário do filme, para que se transforme em diferença tônica, no sistema mnésico, e motive novas realizações, ou seja, novas experimentações do texto e, talvez idealmente, do próprio produto - mas, aqui, a semiótica já não mais pode interferir. Por fim, é assim que, ao trazer o impacto da descoberta da marca e a possibilidade da realização plena, o anúncio minimalista da Budweiser trabalha por arraigar-se na memória do enunciatário.

\section{Desdobramentos}

Tendo concluído a análise na seção anterior, pudemos notar que os métodos da semiótica tensiva retrabalhados e especificados aqui têm uma abrangência que vai além dos limites do objeto sob análise. Faremos, então, nesta seção uma justificativa e uma sugestão de abertura dos procedimentos usados.

Como vimos, a eficácia do anúncio publicitário em questão está em grande medida atrelada à comparação dos dois planos semióticos. Elementos da expressão e do conteúdo se corroboram, criam contrastes e, de maneira geral, interagem para a construção do todo.

A vertente tensiva da teoria semiótica desenvolvida por Claude Zilberberg $(2006 ; 2011 ; 2012)$ toma emprestada categorias do plano da expressão musical, tais como andamento e tonicidade, a fim de criar mecanismos de análise de aspectos do conteúdo não antes contemplados pela teoria. Ainda que tenham sido concebidas no interior da semiótica para o estudo dos estados de alma, a própria herança que acompanha essas categorias sugere a sua aplicação à análise da expressão. Ademais, o caráter generalizante das categorias tensivas torna seu emprego possível para uma larga variedade de objetos.

O fato de que as categorias tensivas sejam aplicáveis aos dois planos da linguagem traz o risco da homologação direta entre uma categoria num e noutro plano. Se o tratamento estético do plano da expressão sugere uma ação sobre o plano do conteúdo - e comparações 
e correlações são o viés para encontrar o sentido desse tratamento -, as correspondências mais pertinentes não são as diretas. Cada plano da linguagem tem sua organização interna e seus elementos estão antes ligados entre si e com o todo que forma esse plano. A comparação que pode homologar categorias de um e outro plano é logicamente posterior a suas análises individuais. Aliás, essa é a mesma lógica da análise do sistema linguístico como um todo.

Como sabemos, a separação entre expressão e conteúdo é essencial para garantir a arbitrariedade do sistema, bem como a sua possibilidade de criação e mudança (HJELMSLEV, 2003, p. 53-87). A análise de uma semiótica se inicia pela separação dos planos e suas análises respectivas são independentes uma da outra (HJELMSLEV, 2003, p. 62-64). Essa separação em planos não conformes é importante, pois distingue uma semiótica de um sistema simbólico, em que não há uma diferença estrutural entre expressão e conteúdo, que estabelecem relação biunívoca entre si - (HJELMSLEV, 2003, p. 116-119). Se expressão e conteúdo fossem imediatamente homologáveis, criando relações "um para um", não existiria necessidade para dois planos e os nomes corresponderiam às coisas do mundo. Para Hjelmslev, os planos da linguagem são solidários: são descritos e construídos de modo análogo, mas suas derivações não se confundem. Uma vez estabelecidos os componentes de cada plano, é por meio da prova da comutação que encontraremos a função que liga os dois planos. ${ }^{14} \mathrm{~A}$ análise de uma semiótica deve, para fins de adequação, respeitar essa divisão, e a análise de cada plano deve-se fazer separadamente.

Assim, partindo da proposta de Zilberberg (2012, p. 45-49), que estabelece as seguintes categorias: (i) espacialidade e temporalidade, na dimensão da extensidade, e (ii) andamento e tonicidade, na dimensão da intensidade, a nossa análise prática nos mostrou, de um lado, a pertinência de sua aplicação aos dois planos do texto separadamente; e, de outro, o ganho em comparar os seus resultados para encontrar a estrutura subjacente e a resultante responsável pela eficácia do texto. A proposta metodológica que fizemos aqui para a utilização das categorias zilberberguianas, ou

\footnotetext{
${ }^{14} \mathrm{~A}$ análise é independente, mas os derivados dos dois planos devem estar em mutação mútua, ou seja, devem passar a prova de comutação e permutação (HJELMSLEV, 2003, p. 139). Não entraremos em detalhes acerca da noção de mutação, pois isso desviaria dos propósitos deste artigo.
} 
seja, o estudo em separado da tensividade nos planos da expressão e do conteúdo, faz mais do que revelar suas estruturas internas. Ao contrastar o funcionamento interno dos dois planos, é possível apontar também tendências e direções que poderiam permanecer em segundo plano ou não explicitadas, se partíssemos indiscriminadamente para a análise dos dois planos, ou se tomássemos apenas um dos planos para o estudo. Nesses termos, esse procedimento ganha amplitude ao criar as condições para o estudo comparativo da tensividades em textos semelhantes, ou ainda nos textos em geral. ${ }^{15}$

\section{Referências}

FONTANILLE, J.; ZILBERBERG, C. Tensão e significação. Tradução de Ivã Carlos Lopes, Luiz Tatit, Waldir Beividas. São Paulo: Discurso Editorial / Humanitas - FFLCH - USP, 2001.

GREIMAS, A. J.; COURTÉS, J. Dicionário de semiótica. Tradução de Alceu Dias Lima et al. São Paulo: Contexto, 2011.

GREIMAS, A. J.; FONTANILLE, J. Sémiotique des passions: des états de choses aux états d'âme. Paris: Seuil, 1991.

HJELMSLEV, L. Prolegômenos a uma teoria da linguagem. $2^{\mathrm{a}}$ ed. São Paulo: Perspectiva, 2003.

LA MONICA, P. Super Prices for Super Bowl Ads. CNN Money. 3 jan. 2007. Disponível em: <http://money.cnn.com/2007/01/03/news/funny/ superbowl_ads/index.htm>. Acesso em: 15 mar. 2009.

LINDENBERG LEMOS, C. Condições semióticas da repetição. 2015. 233 f. Tese (Doutorado em Semiótica e Linguística Geral e Langues et Lettres) - Faculdade de Filosofia, Letras e Ciências Humanas, Universidade de São Paulo, São Paulo; Faculté de Philosophie et Lettres, Université de Liège, Liège (BE), 2015. Disponível em: $<$ http:// www.teses.usp.br/teses/disponiveis/8/8139/tde-09062015-111352/ publico/2015_CarolinaLindenbergLemos_VCorr.pdf $>$. Acesso em: 11 mar. 2016.

. Entre expressões e conteúdos: do semissimbolismo às categorias tensivas. 2010. 109 f. Dissertação (Mestrado em Semiótica e Linguística

\footnotetext{
${ }^{15}$ Para um exemplo de estudo contrastivo de filmes publicitários sob esse princípio, ver Lindenberg Lemos (2010).
} 
Geral) - Faculdade de Filosofia, Letras e Ciências Humanas, Universidade de São Paulo, São Paulo, 2010. Disponível em: <http://www.teses.usp.br/ teses/disponiveis/8/8139/tde-30042010-121008/publico/CAROLINA_ LINDENBERG_LEMOS.pdf>. Acesso em: 11 mar. 2016.

. Cognição e paixão na propaganda. In: CONGRESSO INTERNACIONAL DAASSOCIAÇÃO BRASILEIRA DE ESTUDOS SEMIÓTICOS, 3, 2007. Anais... Vitória: UFES, 2007. vol. único, s/p.

MICHAELIS. Dicionário de Português Online. São Paulo: Melhoramentos. Disponível em: $<$ http://michaelis.uol.com.br/moderno/ portugues/index.php>. Acesso em: 13 jul. 2015.

RAUGUST, K. Bud-Weis-Er: Computer-Generated Frogs and Lizards Give Bud a Boost. Animation World Magazine, n. 3.7, out. 1998. Disponível em: $<$ http://www.awn.com/mag/issue3.7/3.7pages/3.7raugustbud.html $>$. Acesso em: 19 mar. 2009.

TATIT, L. Semiótica da canção: melodia e letra. São Paulo: Escuta, 2007. ZILBERBERG, C. Figure. In: GREIMAS, A. J.; COURTÉS, J. Sémiotique: dictionnaire raisonné de la théorie du langage. Tomo II. Paris: Hachette, 1986, p. 91-93.

. Síntese da Gramática Tensiva. Significação, n. 25, São Paulo, p. 163-204, 2006.

. Louvando o acontecimento. Galáxia, vol. 1, n. 13, p. 13-28, 2007. Tradução de Maria Lúcia Vissotto Paiva Diniz.

. Elementos de semiótica tensiva. São Paulo: Ateliê, 2011.

. La structure tensive suivi de Note sur la structure des paradigmes et de Sur la dualité de la poétique. Liège: PULg, 2012. 